Jasmina Markič

Universidad de Ljubljana

\title{
ACERCA DE LAS PERÍFRASIS VERBALES IR Y VENIR + GERUNDIO EN ESPAÑOL, PORTUGUÉS Y GALLEGO
}

Palabras clave: perífrasis verbal, gerundio, aspecto verbal

\section{Las perífrasis verbales: definiciones y valores}

Partiendo de las propuestas teóricas para las perífrasis verbales en español ${ }^{1}$ el presente artículo analiza los usos más frecuentes de las perífrasis verbales españolas ir y venir + gerundio contrastándolos con algunos usos de las perífrasis verbales equivalentes en portugués (ir y vir + gerúndio) y en gallego (ir y vir + xerundio).

La Nueva Gramática de la Lengua Española (NGLE) de la RAE (2009: 2105) define las perífrasis verbales como «combinaciones sintácticas en las que un verbo auxiliar incide sobre un verbo auxiliado, llamado a veces principal o pleno, construido en forma no personal (es decir, en infinitivo, gerundio o participio) sin dar lugar a predicaciones distintas». En este estudio se parte, por consiguiente, de la definición de las perífrasis verbales como agrupaciones verbales o combinaciones sintácticas de dos (o más verbos en el caso de las agrupaciones perifrásticas o secuencias de auxiliares en las que los verbos auxiliares se pueden encadenar subordinándose unos a otros; de esta manera aparecen las llamadas perífrasis verbales encadenadas, como p. ej. Voy a irme yendo o Van a tener que empezar a dejar de venir por aqui) en las que sólo el primer verbo puede ser flexivo ${ }^{3}$. El verbo auxiliar suele conjugarse (p. ej. Vamos a estudiar física esta tarde) pero puede no estar conjugado debido a las características sintácticas particulares del contexto (p. ej. No es humano tener que trabajar doce horas diarias en condiciones laborales pésimas). Las perífrasis verbales se componen, por lo tanto, de un verbo auxiliar y un verbo auxiliado. La función del auxiliar es primordialmente gramatical, es decir, expresa contenidos gramaticales de modalidad, tiempo, aspecto y voz. Aunque el peso semántico recae sobre el verbo auxiliado, el auxiliar también puede añadir valores léxico-semánticos a la perífrasis verbal ya que la desemantización, siendo esencial en el proceso de gramaticalización, no es homogénea ni obligatoria en el caso de los auxiliares de las perífrasis verbales (García Fernández, 2006: 24). A menudo el auxiliar mantiene su significado original parcial o, en algunos casos, como empezar/comenzar a + infinitivo, pleno. En el caso de los verbos de movimiento en función de auxiliares las perífrasis verbales mantienen frecuentemente un valor semántico de dinamicidad.

\footnotetext{
Véase entre otros a Fernández de Castro, Gómez Torrego, García Fernández, Yllera.

En Javier Marías (1996): Mañana en la batalla piensa en mí. Madrid: Alfaguara, p. 333.

Sin embargo en las perífrasis verbales denominadas copulativas de tipo va y dice, cogió y nos pegó los dos verbos se encuentran en forma flexiva. Véase Coseriu (1977: 79-151).
} 
La noción de aspecto es esencial para estudiar las perífrasis verbales en las lenguas románicas en general. En la opinión de Coseriu (1977) y Dietrich (1983) las perífrasis verbales constituyen un sistema verbal paralelo especializado para la expresión de valores aspectuales. Para los fines de este análisis el concepto de aspecto verbal es considerado más allá de la tradicional división del aspecto verbal en perfectivo e imperfectivo, es decir, abarca además los valores aspectuales como son el modo y la fase de la acción. El aspecto verbal stricto sensu expresa cómo el hablante ve la acción ${ }^{4}$, desde qué punto de vista o perspectiva la observa, es decir, como la focaliza. En el caso de las perífrasis verbales es el paradigma verbal del auxiliar el que desempeña un papel primordial. El hablante puede abarcar la acción globalmente, en su totalidad con el inicio y el final (perspectiva global o perfectiva que en español se suele indicar con el pretérito perfecto simple), puede abarcar una parte de la acción sin interesarle el inicio ni el final (perspectiva cursiva o imperfectiva que en español se suele indicar con el pretérito imperfecto) o una parte de la acción señalando el inicio pero sin indicar el final focalizando una acción desde su inicio hasta un momento central de su desarrollo (perspectiva imperfectiva continuativa, se suele señalar en español con el pretérito perfecto compuesto). Paralelamente a estos valores del aspecto verbal, el término de «valores aspectuales» comprende los siguientes conceptos ${ }^{5}$ : las características del desarrollo de la acción verbal en el tiempo (acciones momentáneas, reiterativas, habituales, resultativas, progresivas, durativas), es decir, el modo de la acción, lo que frecuentemente se denomina Aktionsart; las fases de la acción que se refieren al grado de la realización de la acción (comienzo, mitad y fin: fase inminencial, fase incoativa o ingresiva, fase media o continuativa, fase terminativa); el tipo de la acción: acciones télicas (realizaciones y logros) y atélicas (estados y actividades) referentes a la clasificación de Vendler ${ }^{6}$.

La mayoría de los lingüistas contemporáneos consideran las perífrasis verbales en portugués como estructuras verbales especiales con sus propios valores y funciones. $\mathrm{Cu}-$ nha y Cintra (1984: 393), sin embargo, en su conocida gramática Nova Gramática do Português Contemporâneo dedican poco espacio a las perífrasis verbales que denominan locuciones verbales mencionándolas en los apartados dedicados al aspecto verbal (Aspectos, pp. 380-381) y a los verbos auxiliares (Verbos auxiliares e seu emprego, pp. 393-396). Los dos autores definen estas construcciones perifrásticas de la siguiente manera: «Os conjuntos formados de um verbo auxiliar com um verbo principal chamam-se locuções verbais. Nas locuções verbais conjuga-se apenas o auxiliar, pois o verbo principal vem sempre numa das formas nominais: no particípio, no gerúndio, ou no infinitivo impessoal» (Cunha, Cintra, 1984: 393).

4 En este estudio, si no se indica de otra manera, el término acción significa acción propiamente dicha, proceso y estado.

5 La definición general del concepto de valores aspectuales se desprende de las definiciones de aspecto de los autores Miklič, T. (1983): L'opposizione italiana perfetto vs imperfetto e l'opposizione slovena dovršnost vs nedovršnost nella verbalizzazione delle azioni passate. Linguistica, 23. Ljubljana: Filozofska fakulteta, 53-123; Comrie, B. (1976): Aspect. Cambridge: Cambridge University Press; Coseriu, E. (1980): Aspect verbal ou aspects verbaux? Quelques questions de théorie et de méthode. La notion d'aspect. Colloque organisé par le Centre d' Analyse Syntaxique de 1'Université de Metz. Paris: Klincksieck.; y otros.

6 En García Fernández (2006: 41). 
En la Gramática da Língua Portuguesa (2003) de Mateus et al. las perífrasis verbales de infinitivo son tratadas brevemente como operadores aspectuales o verbos de operación aspectual (2003: 145-151), mientras que las de gerundio y participio no se estudian.

A pesar de que el español, el gallego y el portugués son extremamente ricos en perífrasis verbales y a pesar del hecho de que estas construcciones perifrásticas tienen una gran complejidad de funciones y significados, las gramáticas portuguesas casi no se refieren a ellas. Tampoco existen muchos estudios importantes dedicados únicamente a las perífrasis verbales en portugués. Muchos lingüistas estudian las perífrasis verbales en portugués en el marco de sus investigaciones sobre el aspecto y el modo verbales ${ }^{7}$. Henrique Barroso se dedica al estudio de las perífrasis verbales aspectuales en su obra $O$ aspecto verbal perifrástico em português contemporâneo: visão funcional/sincrónica (1994) siguiendo el modelo definido por Dietrich (1983). Barroso (1994: 13) estudia las perífrasis verbales aspectuales en el marco del aspecto denominado perifrástico y las define como:

[...] um sistema complementar (ou marginal), constituído, formalemente, por verbo auxiliar (= verbo morfemático) + uma forma nominal do verbo principal: infinitivo, gerúndio o particípio.

A incidência do verbo morfemático pode ser directa (do tipo «Venho trabalhando na tese») ou indirecta (tipo: «Estou a trabalhar na tese»).

La gramática gallega (Freixeiro Mato, 2006) define la perífrasis verbal de una manera semejante a la de la gramática española:

En resumo, as perífrasis verbais, como unha clase especial dos complexos verbais, son secuencias constituidas por duas formas verbais, unha como verbo auxiliar en forma finita e outra como verbo auxiliado en infinitivo, xerundio ou participio, que se achan en tal relación de interdependencia que constitúen unha unidade de carácter sintáctico e semántico. [...]

(Freixeiro Mato, 2006: 176)

\section{Las perífrasis verbales de gerundio}

Las perífrasis verbales de gerundio vienen suscitando interés desde hace tiempo. Los filólogos colombianos Miguel Antonio Caro in Rufino José Cuervo ${ }^{8}$ estudiaron la forma y las funciones de estas construcciones perifrásticas que consideraban una rama de la conjugación del verbo. En una de las notas a la Gramática de Andrés Bello (Bello, 1988: 900-904) Cuervo resume el Tratado del participio de Caro, describe las perífrasis verbales con andar, estar, venir + gerundio (que denomina participio) y reflexiona sobre la definición de las perífrasis verbales y sus funciones:

\footnotetext{
Maria Henriqueta Costa Campos (1997), Ataliba Teixeira de Castilho (en Barroso, 1994: 36), Dietrich (1983), etc.

8 Miguel Antonio Caro (1843-1909): Gramática Latina, Tratado del participio.

Rufino José Cuervo (1844-1911): Diccionario de construcción y régimen de la lengua castellana, Notas a la Gramática de Bello, Apuntaciones críticas sobre el lenguaje bogotano.
} 
Amando, en su calidad de participio activo, sirve en segundo lugar para formar tiempos compuestos en unión de un verbo que accidentalmente toma carácter de auxiliar, cuales son estar, andar, venir y algunos otros; combinaciones en que, quedándole al verbo sólo una significación genérica y asumiéndola específica el participio, se forma de las dos una serie de tiempos compuestos en que el participio hace el principal papel, y que por esta razón puede considerarse como una rama de la conjugación del verbo de que sale el participio; así yo estoy pensando, más denota la idea de pensar que la de estar; y es como una forma enfática de pienso: «Don Quijote, que se vio libre, acudió a subir sobre el cabrero, el cual, lleno de sangre el rostro, molido a coces de Sancho, andaba buscando a gatas algún cuchillo de la mesa para hacer alguna sanguinolenta venganza» (Cervantes): el circunloquio andaba buscando dice mucho más que diría la forma simple buscaba. (Bello, 1988: 901-902)

En las perífrasis verbales de gerundio el verbo auxiliado en gerundio está relacionado directamente con el verbo auxiliar sin ningún tipo de nexos. Es importante distinguir la estructura perifrástica de la no perifrástica en la que el gerundio es complemento directo de un verbo de percepción: La vimos presentando su libro (en este caso es posible construir una oración subordinada sustantiva, lo que es una prueba importante de que se trata de una construcción no perifrástica: La vimos que presentaba su libro) o hace parte de una oración subordinada adverbial de gerundio (Venían cantando canciones populares). Las perífrasis verbales de gerundio se caracterizan por ser incompatibles entre sí, a diferencia de las de infinitivo, que pueden encadenarse; este hecho es indicio de que las perífrasis verbales de gerundio forman un subsistema de términos mutuamente excluyentes (RAE NGLE, 2009: 2185). Pero algunas sí se pueden combinar con las perífrasis verbales de infinitivo (RAE NGLE, 2009: 2190), p. ej.: Tampoco vamos a estar comiendo todo el día. La negación de la forma no personal en las perífrasis verbales de gerundio tiende a presentarse mediante «sin + infinitivo» (RAE NGLE, 2009: 2186), p. ej.: Estuvo sin comer durante días.

Entre los valores que se expresan con las perífrasis verbales de gerundio predominan los aspectuales ${ }^{9}$, no obstante con algunas perífrasis verbales se indican valores temporales (p. ej., en algunos casos, estar + gerundio con el auxiliar en presente de indicativo puede tener valor de presente actual), modales (p. ej. el valor aproximativo en el enunciado Este coche viene costando 10.000 euros). Algunas perífrasis verbales de gerundio denominadas perífrasis verbales discursivas funcionan como marcadores de discurso (García Fernández, 2006: 52): empezar/comenzar + gerundio como marcadores de apertura y acabar/terminar + gerundio como marcadores de cierre. A menudo las perífrasis verbales añaden valores estilísticos al enunciado ${ }^{10}$.

\section{Ir + gerundio}

$I r+$ gerundio es, en español, una perífrasis verbal aspectual con la que se expresa el avance gradual de una acción de un alto grado de gramaticalización (García Fernández,

\footnotetext{
9 «Las perífrasis de gerundio muestran una acción, un proceso o un estado de cosas en curso. Puede decirse, por tanto, que son todas aspectuales» (RAE NGLE, 2009: 2185).

10 Véase Gómez Torrego (1970).
} 
2006: 172) ${ }^{11}$. Con ir + gerundio el hablante acentúa el transcurrir progresivo y la duración de la acción. El lento desarrollar de la acción se refuerza con complementos circunstanciales de tiempo o modo. Tiene un fuerte valor expresivo y se usa a menudo para describir, acentuar el lento progresar de las acciones, inmovilizar las acciones en el tiempo. Se usa tanto en la perspectiva cursiva (el lento progresar y la duración se acentúan) como en la perspectiva global (el progresar y el durar de la acción se ven como terminados $)^{12}$. Expresa cambios graduales, por lo que es incompatible con los instantáneos (p.ej.: El río creció de golpe pero no *Fue creciendo de golpe) (RAE NGLE, 2009: 2196). Frecuentemente viene acompañada de expresiones adverbiales que indican progresión (poco a poco, paulatinamente, gradualmente, progresivamente, de modo paulatino ...), lo que destaca la intensificación gradual que expresa. También aparece con locuciones adverbiales o grupos preposicionales (con el paso del tiempo, a lo largo de los años, al paso de los días ...) que indican el período al que corresponde el cambio progresivo.

Siempre fue una católica practicante, como toda su familia, y en especial la madre, y su devoción se iría haciendo más intensa y profunda con el paso del tiempo, hasta alcanzar estados de misticismo. (García Márquez, 1996: 70)

Ella había ido descubriendo poco a poco la incertidumbre de los pasos de su marido, sus trastornos de humor, las fisuras de su memoria, su costumbre reciente de sollozar dormido, pero no los identificó como los signos inequívocos del óxido final, sino como una vuelta feliz a la infancia. (García Márquez, 1985b: 42)

El hablante «frena» el progresar de la acción como si una cámara enfocara e inmovilizara un fragmento de la narración desarrollándola lentamente. Este carácter progresivo hace que esta perífrasis verbal sea un recurso estilístico importante en las descripciones. La perífrasis verbal tiene un fuerte valor expresivo y es muy adecuada para obtener determinados efectos de desaceleración de la narración produciendo imágenes de prolongación lenta, pausada. (Gómez Torrego, 1988: 163)

En su itinerario nocturno la canoa pontificia se había ido llenando de costales de yuca, racimos de plátanos verdes y huacales de gallinas, y de hombres y mujeres que abandonaban sus ocupaciones habituales para tentar fortuna con cosas de vender en los funerales de la Mamá Grande. (García Márquez, 1985a: 91)

Esta perífrasis verbal aparece en todos los paradigmas verbales. Así, por ejemplo, con el auxiliar en pretérito perfecto simple se señala una acción perfectiva acentuando su

${ }^{11}$ Esta perifrasis verbal era más frecuente que estar + gerundio en la lengua medieval. En el siglo XIX estar + gerundio comienza a superarla en frecuencia y usos (RAE NGLE, 2009: 2192). Šmid (2009: 87), en su investigación sobre el judeoespañol en Bosnia, constata que la perífrasis ir + gerundio aparece con bastante frecuencia en su valor aspectual durativo progresivo (cita algunos ejemplos como: las van recogendo y arebatando; lo va alevantando y se va alynpiyando, se van meneando ...).

${ }^{12}$ Según el modelo de Coseriu y Dietrich esta perífrasis verbal se insiere en la vision prospectiva, es decir, expresa una acción verbal que se «ve» entre los puntos C y B del citado modelo. 
desarrollo paulatino hasta el término de la acción (perspectiva global); con el auxiliar en pretérito imperfecto se acentúan el desarrollo progresivo y la duración de la acción sin indicar su término (perspectiva cursiva).

Poco a poco, sin embargo, y a medida que la guerra se iba intensificando y extendiendo, su imagen se fue borrando en un universo de irrealidad. (García Márquez, 1986a: 132)

De modo que el presidente se quitó y fue poniendo sobre la cama el anillo matrimonial, el reloj con la leontina y las mancuernas y el pisacorbatas que estaba usando. (García Márquez, 1992: 51)

Un remolcador descendía por el Ródano con un radio a todo volumen que iba dejando por las calles un reguero de música. (García Márquez, 1992: 52)

La perífrasis verbal ir + gerundio conserva en parte el sentido original de ir como verbo de movimiento en la noción de progresión o de desarrollo lineal que la caracteriza. Se construye preferentemente con predicados télicos, y suele ser incompatible con predicados atélicos (en el sentido de eventos sin límite natural, p. ej. *Te fui esperando), salvo cuando los predicados atélicos o durativos adquieren acepciones compatibles con el límite que ir + gerundio requiere, p.ej. El médico fue viendo a los pacientes uno por uno (RAE NGLE, 2009: 2192-2193).

En el marco de una acción progresiva la perífrasis verbal puede adquirir un matiz incoativo o ingresivo ${ }^{13}$ sobre todo si el auxiliar se halla en presente y en imperativo:

-Y ahora - dijo -vayan pasando uno por uno. Hasta mañana a esta misma hora estoy aquí para resolver problemas. (García Márquez, 1986b: 25)

-Pues habrá que ir abriendo. -Floro se quitó la sotana con un suspiro de tristeza-. (Muñoz Molina, 1988: 82)

La perífrasis verbal puede llevar como verbo principal ir, es decir, que tanto el auxiliar como el auxiliado pueden ser el mismo verbo o puede aparecer en agrupaciones perifrásticas con el mismo verbo:

La gente se iba yendo poco a poco. (Gómez Torrego, 1988: 160)

¿Qué hora es?

Llevaba reloj en esa mano como una zurda, era una pregunta retórica para ganar tiempo, o quizá temía volcar el vaso si giraba la muñeca para mirarlo.

-La una, casi -contesté. Estuve a punto de derramar mi grappa.

${ }_{13}$ Ir + gerundio permite visualizar el punto inicial o final del proceso del que se habla. El primero da lugar a menudo a interpretaciones ingresivas (incoativas). Este hecho (visualización del punto inicial del proceso) explica asimismo que $i r$ + gerundio pueda aparecer en forma imperativa (RAE NGLE, 2009: 2192). 
-Es tarde. Voy a irme yendo. -«Tres veces el mismo verbo», pensé, «cómo matizan también nuestras lenguas, como las antiguas. 'Voy a irme yendo' indica que no se va todavía, va a esperar todavía un poco, por lo menos hasta que se beba la mitad de se whisky, aunque se lo beberá muy rápido, le ha vuelto a entrar prisa porque le he pedido algo y no querrá arriesgarse a que le pida más cosas. Dentro de un rato dirá 'Voy a irme' y aún más tarde dirá 'Me voy', y sólo entonces se irá de veras.» (Marías, 1996: 333)

La NGLE (2009: 2193) menciona que en algunas partes de Hispanoamérica (México, parte de Centroamérica, el Caribe continental, algunos países andinos como Ecuador) ir + gerundio se usa con el auxiliar en el pretérito imperfecto para expresar conato o acción inminente no llevada a cabo, como p. ej. La iban matando = Casi la matan.

Se podrían utilizar los mismos criterios explicativos también para las perífrasis verbales en gallego y portugués.

Freixeiro Mato (2006: 181-183) clasifica la perífrasis verbal gallega $i r+x e r u n d i o$, equivalente en casi todos los valores con las correspondientes perífrasis verbales española y portuguesa, como perífrasis verbal «imperfectiva». La define como perífrasis verbal que presenta la acción en su duración, como proceso en desarrollo, y que indica, además, el desarrollo gradual de la acción marcada por una progresión continua que puede ir reforzada por algún adverbio o locución adverbial.

A Galiza vai perdendo populación ano tras ano. (Freixeiro Mato, 2006: 182)

Foi deixando pouco a pouco aquel costume. (ibídem)

De primeiras non tiña unhas faccións moi ben definidas, pero conforme Abundio Domínguez o ía desprendendo das redes e das algas, e lle arrincaba cunha navalla os percebes e mexillóns que levaba aferrados ao corpo, foise descubrindo un homiño pequeno e gordecho, algo vello, que sorría por baixo da mesta barba verdosa con ollos de sardiña feliz. (Solleiro, 2001: 11-12)

A pesar de que en gallego prevalece con este valor, la perífrasis verbal ir + gerundio, en ocasiones, y a diferencia del español donde esta sustitución no se da, es posible también la construcción con el llamado infinitivo gerundial (ir a + infinitivo) que se diferencia de la perífrasis verbal temporal gallega $i r+$ infinitivo con valor temporal de futuro (p. ej. Vas perder diñeiro - Freixeiro Mato, 2006: 178) por la presencia de la preposición a como elemento de enlace: Sempre vai a ler (vai lendo) no autobús (Freixeiro Mato, 2006: 183).

En portugués Cunha y Cintra (1984: 380) definen esta perífrasis verbal como portadora del aspecto continuo que tiene que ver con el proceso del desarrollo de la acción. Indica que la acción se realiza progresivamente o por etapas sucesivas (ibídem 395) ${ }^{14}$.

${ }^{14}$ Ir + infinitivo en portugués expresa una intención firme para realizar una acción (valor modal), la inminencia de la acción (valor aspectual) y, en la lengua hablada en Brasil, el futuro próximo (valor temporal):

Vou ler este livro. O trem vai partir. O professor vai explicar hoje as conjugações compostas. 
Vou lendo Os Lusíadas. (Cunha, Cintra, 1984: 380)

Os convidados iam chegando de automóvel (sucessivamente). (Cunha, Cintra, 1984: 395)

O navio ia encostando ao cais (pouco a pouco). (ibídem)

Olga Mata Coimbra e Isabel Coimbra en su Gramática Activa 2 (portugués para extranjeros) destacan el aspecto durativo de la perífrasis verbal y afirman que la perífrasis verbal ir en presente de indicativo + gerundio indica duración de una acción que está por iniciarse o está en curso (2000: 72):

Vai andando, que eu já lá vou ter.

Enquanto as lojas não abrem, vou vendo as montras.

Con el auxiliar en pretérito imperfecto de indicativo esta perífrasis verbal denota, según las autoras mencionadas, la realización gradual de una acción que se desarrolla poco a poco o una acción que está a punto de realizarse pero no se realiza:

As notícias iam chegando ao longo do dia.

O pavimento está muito escorregadio; já ia caindo por duas vezes. (ibídem)

Con el pretérito perfecto simple la perífrasis verbal ir + gerundio expresa duración de una acción pasada (perfectiva):

Enquanto não chegavas, fui fazendo o jantar. (ibídem)

Barroso (1994: 97-98) clasifica esta perífrasis verbal altamente funcional y de uso muy frecuente dentro de la subcategoría aspectual de visión prospectiva según el modelo de Dietrich (1983). Aparece en todos los paradigmas verbales y tiene un alto grado de gramaticalización. El autor comprueba que es más frecuente con los verbos imperfectivos o atélicos (prolongar, fazer, trabalhar, construir, sofrer, decorrer, ficar ...) pero también aparece con los verbos perfectivos o télicos (apagar, descobrir, esquecer ...).

Desde o instante em que entrou na clínica, ela foi ficando muito preocupada. (Machado, 1986: 26)

E quando a neném foi sossegando, ficou tão bonitinha que a menina pensou que a cara dela não combinava nada com o nome de Cusfosfós. (Machado, 1986: 44)

Como en español y en gallego ${ }^{15}$ también en portugués la perífrasis verbal puede llevar como verbo principal $i r$, es decir, que tanto el auxiliar como el auxiliado pueden ser el mismo:

Como vais? -Vou indo. (Barroso, 1994: 100)

15 «Nesta perífrase o xerundio pode pertencer ao mesmo verbo ir do auxiliar (ir indo), construción, moi frecuente na fala popular, aínda que non sempre constitúa perífrase.» (Freixeiro Mato, 2006: 183). 


\section{Venir + gerundio}

La perífrasis verbal venir + gerundio es, en español, una perífrasis verbal aspectual continuativa ${ }^{16}$ que abarca una acción desde su inicio hasta un punto central de su desarrollo sin señalar su final (García Fernández, 2006: 268). Expresa una acción en desarrollo, característica propia de todas las perífrasis verbales de gerundio. Según la NGLE (2009: 2201) venir + gerundio indica el inicio del proceso en un punto anterior al momento del habla o referencia que posiblemente se prolongará más allá de él (p. ej.: Nos viene ocultando sus verdaderas intenciones).

Manifiesta algunas restricciones que se deben a la orientacion deíctica del auxiliar venir, que señala acercamiento hacia el hablante desde un determinado punto. En este sentido no puede expresar alejamiento presentando así una perspectiva contraria a la de $i r+$ gerundio cuando indica un movimiento que se proyecta desde el espacio-tiempo del hablante hacia adelante (p. ej.: El tren se viene acercando / el tren se va alejando).

Los paradigmas verbales que con más frecuencia aparecen con esta perífrasis verbal son el presente y el imperfecto por ser ambos paradigmas imperfectivos que no focalizan el final de la acción, en este caso la perífrasis verbal suele indicar acción durativa-progresiva. Suele ir acompañada de adverbiales temporales desde hace mucho tiempo, hasta ahora, hasta la fecha, hasta entonces, etc. que destacan el inicio previo de la acción y su desarrollo hasta un momento dado.

Este captó la idea de inmediato, pues él también venía pensando desde hacía tiempo en una manera de judicializar el problema del narcotráfico. (García Márquez, 1996: 84)

La más bajita acababa de robar una botella de ron, cosa que por el volumen de la cintura parecía venir haciendo desde rato atrás. (CREA) $)^{17}$

La perífrasis verbal es menos frecuente con los tiempos perfectivos que con los imperfectivos. Sin embargo, aparecen tanto el pretérito perfecto compuesto ${ }^{18}$ como también el pretérito perfecto simple (con más frecuencia en el español de América donde, en algunos valores, sobre todo temporales, el pretérito perfecto simple sustituye al pretérito perfecto compuesto):

Recuerde, doctor Villamizar, que la extradición ha cobrado muchas víctimas, y sumarle dos nuevas no alterará mucho el proceso ni la lucha que se ha venido desarrollando. (García Márquez, 1996: 215)

${ }^{16}$ La visión retrospectiva en Dietrich (1983: 210) que considera la progresividad de la acción desde el punto a de la visión hasta el momento del habla.

${ }^{17}$ RAE: Banco de datos (CREA) [en línea]. Corpus de referencia del español actual: http://www.rae.es (10-082011).

18 Abarca una parte de la acción señalando el inicio pero sin indicar el final focalizando una acción desde su inicio hasta un momento central de su desarrollo (perspectiva imperfectiva continuativa - se suele señalar en español con el pretérito perfecto compuesto). 
En Navidad vinieron diciendo que habían alquilado una cabaña junto a un lago, en un bosque, iríamos a pasar allí la Nochevieja [...]. (Muñoz Molina, 1988: 92)

-Yo lo sé -dijo ella-. La noche que se metieron en el salón de billar el negro estaba con Gloria, y pasó todo el día siguiente en su cuarto hasta por la noche. Después vinieron diciendo que lo habían cogido en el cine. (García Márquez, 1985a: 29)

En ocasiones puede tomar un valor modal aproximativo, derivado de su significado de acercamiento al ámbito temporal del hablante. En este caso es más frecuente la perífrasis verbal venir a + infinitivo (Este coche viene costando 10.000 euros / Este coche viene a costar 10.000 euros).

En el español de América hablado en algunos países andinos (sur de Colombia, Ecuador, Perú) venir + gerundio adquiere un valor temporal de pasado reciente (Ya vengo comiendo = Acabo de comer) similar al de la perífrasis verbal acabar de + infinitivo y semejante al valor de la perífrasis verbal francesa venir de + infinitivo o portuguesa, vir de + infinitivo, considerada por algunos gramáticos como galicismo (p. ej.: Minha intenção era saudar os jangadeiros que vêm de chegar (Cunha, Cintra, 1994: 396)).

En gallego la perífrasis verbal que corresponde a la española venir + gerundio es vir + xerundio (y su sinónimo vir a +xerundio). Se clasifica dentro del grupo de las perífrasis aspectuales «imperfectivas», es decir, según la definición de Freixeiro Mato (2006), las que presentan la acción en su duración como proceso en desarrollo. También expresa un movimiento hacia el hablante e indica desarrollo progresivo de la acción visto desde un momento situado anteriormente.

Eu xa o viña ouvindo desde rapaz. (Freixeiro Mato, 2006: 183)

Quen me veña lendo desde que comezamos a publicar vai a pensar que son un puto chorón, que non fago máis que queixarme, que non merecemos perder contra Pepe Noya, que o resultado contra Boqueixón debeu ser outro, que con Maderas Ramos eles só crearon a ocasión de gol, etc. pero e que é certo, non podo comentar os partidos xogados doutra maneira (excepción feita no partido con Ventosa que merecemos perder e empatamos): http://metalnoiaveteranos.blogspot.com/2010/10/don-budi-metal-noia-1-0.html (08-08-2011)

A diferencia del español, en gallego la perífrasis verbal de gerundio vir a + infinitivo (denominado infinitivo gerundial) puede ser imperfectiva con valor aspectual progresivocontinuativo equivalente a vir + xerundio. Sin embargo en este uso es poco frecuente ${ }^{19}$ :

Veño lendo un libro por día. -Veño a ler un libro por día.

(Freixeiro Mato, 2006: 183)

19 En vir a + infinitivo prevalece el valor aspectual terminativo: Todos viñam a casar no final (Freixeiro Mato, 2006: 187). De este aspecto terminativo deriva el valor modal aproximativo cuando la forma vir $a+$ infinitivo puede sustituirse por vir + xerundio: A leira veulle a custar /veulle custando cinco millóns (Freixeiro Mato, 2006: 187). 
En las perífrasis verbales de gerundio en portugués también prevalece el valor aspectual continuativo, es decir, de desarrollo de la acción, progresión y continuidad. La perífrasis verbal portuguesa vir + gerúndio ${ }^{20}$ equivalente en muchos de sus valores a la española venir + gerundio, se usa para señalar que la acción se desarrolla gradualmente:

Vinha rompendo a madrugada.

Venho tratando desse assunto. (Cunha, Cintra, 1984: 395)

Barroso (1994: 100-102) clasifica esta perífrasis verbal dentro de la subcategoría aspectual de visión retrospectiva (definida por Dietrich, 1983): «A visão retrospectiva designa a consideração dinâmica da acção verbal entre os pontos A e C. Rigorosamente à semelhança da visão prospectiva (mas em sentido inverso) entre um ponto anterior e o ponto C. Pronto, a progressividade também a caracteriza» (Barroso, 1994: 100). Además de la progresividad (del desarrollo de la acción de un momento temporal-espacial anterior al momento del enunciado o punto referencial) también puede señalar la duración. Es una perífrasis verbal menos frecuente en la norma portuguesa.

Quem venha seguindo com suficiente atenção este relato, terá já estranhado que depois do divertido episódio da patada que salomão aplicou ao padre da aldeia não tenha havido referência a outros encontros com os habitantes destas terras [...]. (Saramago, 2008: 109)

Tinha vezes que ela dizia um deles e lá vinha alguém dizendo que era palavrão. (Machado, 1986: 16)

Então será preciso racionar os alimentos que vierem chegando, disse uma voz de mulher. (Saramago, 1999: 96)

\section{BIBLIOGRAFÍA}

Barroso, H. (1994): O aspecto verbal perifrásico em português contemporâneo: visão funcional/ sincrónica. Porto: Porto Editora.

Bello, A. (1847/1988): Gramática de la lengua castellana destinada al uso de los americanos, I, II con las notas de Rufino José Cuervo. Estudio y edición de Ramón Trujillo. Madrid: Arco Libros.

Campos, M. H. C. (1997): Tempo, Aspecto e Modalidade. Estudos de Linguística Portuguesa. Porto: Porto Editora.

Coimbra, O. M., Coimbra, I. (2000): Gramática Activa 2. Lisboa-Porto-Coimbra: Lidel.

\footnotetext{
${ }^{20}$ Según afirman Cunha y Cintra (1994: 395) vir + infinitivo se usa para indicar movimiento en dirección de un fin determinado o intención: Vieste interromper-me o trabalho; vir a + infinitivo para expresar el resultado final de la acción: Vim a saber dessas coisas muito tarde.
} 
Coseriu, E. (1977): Estudios de lingüística románica. Madrid: Gredos.

Coseriu, E. (1980): «Aspect verbal ou aspects verbaux? Quelques questions de théorie et de méthode». En: La notion d'aspect. Colloque organisé par le Centre d'Analyse Syntaxique de 1’Université de Metz. Paris: Klincksieck.

Cunha, C., Cintra, L. (1984): Nova gramática do português contemporâneo. Lisboa: Edições João Sá da Costa.

Dietrich, W. (1983): El aspecto verbal perifrástico en las lenguas románicas. Madrid: Gredos.

Fernández de Castro, F. (1999): Las perifrasis verbales en el español actual. Madrid: Gredos.

Freixeiro Mato, X. R. (2006): Manual de gramática galega. Vigo: Edicións A Nosa Terra.

García Fernández, L. (2006): Diccionario de perifrasis verbales. Madrid: Gredos.

Gómez Torrego, L. (1970): «La estilística de las perífrasis verbales». En: Homenaje Universitario a Dámaso Alonso. Madrid: Gredos, 85-96.

Gómez Torrego, L. (1988): Perifrasis verbales. Sintaxis, semántica y estilística. Madrid: Arco/ Libros.

Markič, J. (1990): «Sobre las perífrasis verbales en español», Linguistica, 30, 169-206.

Markič, J. (2006): «Valores y usos de las perífrasis verbales de gerundio con los auxiliares ir, andar y venir». Linguistica, 46, 2. Ljubljana: Filozofska fakulteta, 243-250.

Mateus, H. M. M. et al (2003): Gramática da Língua Portuguesa. Lisboa: Editorial Caminho

Miklič, T. (1983): «L'opposizione italiana perfetto vs imperfetto e l'opposizione slovena dovršnost vs nedovršnost nella verbalizzazione delle azioni passate». Linguistica, 23. Ljubljana: Filozofska fakulteta, 53-123.

Real Academia Española/Asociación de Academias de la Lengua Española (2009): Nueva Gramática de la Lengua Española. Madrid: Espasa.

Šmid, K. (2009): Caracterización del judeoespañol de Bosnia a través del «Šéfer Méšec Betí» de Eliézer Papo. Tesis doctoral inédita. Ljubljana: FF UL.

Yllera, A. (1999): «Las perífrasis verbales de gerundio y participio»: En: I. Bosque y V. Demonte (eds.), Gramática descriptiva de la lengua española. Madrid: Espasa-Calpe, 3391-3441.

\section{TEXTOS CITADOS}

García Márquez, G. (1985a): Los funerales de la Mamá Grande. Bogotá: Editorial La Oveja Negra.

García Márquez, G. (1985b): El amor en los tiempos del cólera. Bogotá: Editorial La Oveja Negra.

García Márquez, G. (1986a): Cien años de soledad, Bogotá: Editorial La Oveja Negra.

García Márquez, G. (1986b): La increible y triste historia de la cándida Eréndira y de su abuela desalmada. Bogotá: Editorial La Oveja Negra.

García Márquez, G. (1996): Noticia de un secuestro. Barcelona: Grijalbo Mondadori. 
García Márquez, G. (1992): Doce cuentos peregrinos. Madrid: Mondadori.

Machado, A.M. (1986): Palavras, palavrinhas, palavrões. São Paulo: Quinteto Editorial.

Marías, J. (1996): Mañana en la batalla piensa en mí. Madrid: Alfaguara.

Muñoz Molina, A. (1988): El inviernoi en Lisboa. Barcelona: Seix Barral.

Saramago, J. (1999): O ensaio sobre a cegueira. Lisboa: Editorial Caminho.

Saramago, J. (2008): A viagem do elefante. Lisboa: Editorial Caminho.

Solleiro, S. (2001): Elexías a deus e ao diaño. Vigo: Edicións Xerais de Galicia.

\section{O GLAGOLSKIH PERIFRAZAH IR IN VENIR Z GERUNDIJEM V ŠPANŠČINI, PORTUGALŠČINI IN GALICIJŠČINI}

Ključne besede: glagolska perifraza, gerundij, glagolski aspekt

Prispevek obravnava dve glagolski perifrazi z glagoloma gibanja kot pomožnikoma $\mathrm{v}$ treh jezikih Iberskega polotoka, španščini, portugalščini in galicijščini. Poudarja aspektualno vrednost glagolskih perifraz ir + gerundio in venir + gerundio in primerja njihovo rabo $\mathrm{v}$ treh sorodnih jezikih. Odstopanj v rabi skoraj ni, pri definicijah glagolskih perifraz $\mathrm{v}$ treh jezikih pa so manjše razlike. Z glagolsko perifrazo ir + gerundio govorec poudarja progresiven potek in trajanje dejanja s pomenskim odtenkom razpršenega gibanja brez določene usmeritve. Dejanje se razvija postopno, počasi, kar poleg glagolske perifraze poudarjajo še prislovna določila časa ali načina. Glagolska perifraza venir + gerundio označuje trajajoče, progresivno dejanje, ki se razvija od določene točke do časovno-prostorskega območja, kjer se nahaja govorec. Smer gibanja je torej drugačna od tiste, ki jo označuje ir + gerundio, ki izhaja iz točke, kjer se nahaja govorec, in je usmerjena naprej. Ta odtenek v gibanju prinaša glagol venir / vir, ki v španščini, portugalščini in galicijščini označuje gibanje v smeri proti govorcu. 